Скопје, Македонија

\title{
$n$-EXPONENTIAL CONVEXITY FOR LEVINSON TYPE INEQUALITIES AND RELATED STOLARSKY TYPE MEANS
}

\author{
ANA VUKELIĆ
}

\begin{abstract}
Starting from the result given in [?] where the author gave the generalized Hadamard inequality, we give the generalizations of Levinson's inequality (see [?]) and related inequalities. Also, we investigate the exponential convexity of differences of the left-hand and right-hand side of these inequalities. Using these differences, we produce new exponentially convex functions. They are used in studying Stolarsky type means.
\end{abstract}

\section{INTRODUCTION}

Let $f$ be a real-valued function defined on the segment $[a, b]$. The divided difference of order $n$ of the function $f$ at distinct points $x_{0}, \ldots, x_{n} \in[a, b]$, is defined recursively (see [?], [?]) by

$$
f\left[x_{i}\right]=f\left(x_{i}\right),(i=0, \ldots, n)
$$

and

$$
f\left[x_{0}, \ldots, x_{n}\right]=\frac{f\left[x_{1}, \ldots, x_{n}\right]-f\left[x_{0}, \ldots, x_{n-1}\right]}{x_{n}-x_{0}} .
$$

The value $f\left[x_{0}, \ldots, x_{n}\right]$ is independent of the order of the points $x_{0}, \ldots, x_{n}$. The definition may be extended to include the case that some (or all) of the points coincide. Assuming that $f^{(j-1)}(x)$ exists, we define

$$
f[\underbrace{x, \ldots, x}_{j-\text { times }}]=\frac{f^{(j-1)}(x)}{(j-1) !} .
$$

2000 Mathematics Subject Classification. 26D15, 26D20, 26 D99.

Key words and phrases. Levison inequality, $n$-convex function, $n$-exponentially convexity, means. 
A function $f:[a, b] \rightarrow \mathbb{R}$ is said to be $n$-convex if $n$-th order divided difference of $f$ satisfies

$$
f\left[x_{0}, \ldots, x_{n}\right] \geq 0 \text { for all } a \leq x_{0}<\ldots<x_{n} \leq b .
$$

Now, the well known Levinson inequality is given in the following theorem (see [?]):

Theorem 1. Let $f$ be a real valued 3 -convex function on $[0,2 a]$. Then for $0<x_{k}<a, p_{k}>0(1 \leq k \leq n)$ and $P_{k}=\sum_{i=1}^{k} p_{i}(2 \leq k \leq n)$ we have

$$
\begin{aligned}
& \frac{1}{P_{n}} \sum_{k=1}^{n} p_{k} f\left(x_{k}\right)-f\left(\frac{1}{P_{n}} \sum_{k=1}^{n} p_{k} x_{k}\right) \\
\leq & \frac{1}{P_{n}} \sum_{k=1}^{n} p_{k} f\left(2 a-x_{k}\right)-f\left(\frac{1}{P_{n}} \sum_{k=1}^{n} p_{k}\left(2 a-x_{k}\right)\right) .
\end{aligned}
$$

In [?], J. Pečarić proved the following similar result:

Theorem 2. Let $f$ be a real-valued 3 -convex function on $[0,2 a]$ and $x_{k}(1 \leq$ $k \leq n) n$ points on $[0,2 a]$. Then

$$
\frac{1}{P_{n}} \sum_{k=1}^{n} p_{k} f\left(x_{k}\right)-f\left(\frac{1}{P_{n}} \sum_{k=1}^{n} p_{k} x_{k}\right) \leq \frac{1}{P_{n}} \sum_{k=1}^{n} p_{k} f\left(a+x_{k}\right)-f\left(\frac{1}{P_{n}} \sum_{k=1}^{n} p_{k}\left(a+x_{k}\right)\right) \text {. }
$$

In [?], the authors introduced Levinson means of Cauchy's type using the above inequalities. See also [?], [?], [?] and [?].

The goal of this paper is to give mean value theorems using improvements of Levinson's and related inequalities. Further, the obtained Cauchy type mean value theorems is used in studying Stolarsky type means. The notion of $n$-exponentially convex functions is introduced and a method of producing $n$-exponentially convex functions is deduced. Some known families of functions of the same type are used.

\section{An IMPROVEMENTS OF LEVINSON'S INEQUALITY AND RELATED RESULTS}

Let

$$
E_{n-1}=\left\{\left(u_{1}, \ldots, u_{n-1}\right): u_{i} \geq 0(1 \leq i \leq n-1), u_{1}+\cdots+u_{n-1} \leq 1\right\}
$$

denote the Euclidian simplex and for $u=\left(u_{1}, \ldots, u_{n-1}\right) \in E_{n-1}$, put $u_{n}:=$ $1-\sum_{i=1}^{n-1} u_{i}$. Throughout the paper $n \geq 2$ and $\mu$ is an arbitrary probability 
measure on $E_{n-1}$. The weights $\mu_{i}(1 \leq i \leq n)$ of the measure $\mu(\cdot)$ are defined by

$$
\mu_{i}:=\int_{E_{n-1}} u_{i} d \mu(u)
$$

and so $\mu_{i} \geq 0$ with $\sum_{i=1}^{n} \mu_{i}=1$ and $\left(\mu_{1}, \ldots, \mu_{n}\right)$ may be taken as a set of probability weights.

We denote by $x=\left(x_{1}, \ldots, x_{n}\right)$ a real $n$-tuple with

$$
x_{\min }:=\min (x)<\max (x)=: x_{\max } .
$$

The inner product of vectors $x, y \in \mathbb{R}^{n}$ will be denoted by $x \cdot y$. Let $f:\left[x_{\min }, x_{\max }\right] \rightarrow \mathbb{R}$ be convex. The inequality

$$
f\left(\sum_{i=1}^{n} \mu_{i} x_{i}\right) \leq \int_{E_{n-1}} f(u \cdot x) d \mu(u) \leq \sum_{i=1}^{n} \mu_{i} f\left(x_{i}\right)
$$

has been established in [?] and will be referred to as the generalized Hadamard inequality. Both inequalities in (??) are reversed if $f$ is concave on $\left[x_{\min }, x_{\max }\right]$.

In [?], using (??), authors derived a generalization of the Levinson's inequality which has generalized-Hadamard form:

Theorem 3. Let $f:[0,2 a] \rightarrow \mathbb{R}$ be 3 -convex. Then for $x_{i} \in(0, a)$, we have

$$
\begin{aligned}
f\left(\sum_{i=1}^{n} \mu_{i}\left(2 a-x_{i}\right)\right)-f\left(\sum_{i=1}^{n} \mu_{i} x_{i}\right) & \leq \int_{E_{n-1}}[f(u \cdot(2 a-x))-f(u \cdot x)] d \mu(u) \\
& \leq \sum_{i=1}^{n} \mu_{i}\left[f\left(2 a-x_{i}\right)-f\left(x_{i}\right)\right]
\end{aligned}
$$

Lemma 1. If $f:[0,2 a] \rightarrow \mathbb{R}$ is 3 -convex, then $f(a+t)-f(t)$ is convex on $[0, a]$.

By combining this result with (??), we derive a generalization of the inequality (??) which has generalized-Hadamard form:

Theorem 4. Let $f:[0,2 a] \rightarrow \mathbb{R}$ be 3 -convex. Then for $x_{i} \in[0, a]$, we have

$$
\begin{aligned}
f\left(\sum_{i=1}^{n} \mu_{i}\left(a+x_{i}\right)\right)-f\left(\sum_{i=1}^{n} \mu_{i} x_{i}\right) & \leq \int_{E_{n-1}}[f(u \cdot(a+x))-f(u \cdot x)] d \mu(u) \\
& \leq \sum_{i=1}^{n} \mu_{i}\left[f\left(a+x_{i}\right)-f\left(x_{i}\right)\right]
\end{aligned}
$$


Example 1. Suppose $f(t)=\ln t$, so that $f(t)$ is 3 -convex on $[0,1]$. Let $x_{i} \in[0,1],(i=1, \ldots, n)$, where $n \geq 2$. From (??) with $a=\frac{1}{2}$ we obtain

$$
\frac{\prod_{i=1}^{n} x_{i}^{\mu_{i}}}{\prod_{i=1}^{n}\left(\frac{1}{2}+x_{i}\right)^{\mu_{i}}} \leq \frac{I\left(x_{1}, \ldots, x_{n} ; \mu\right)}{I\left(\frac{1}{2}+x_{1}, \ldots, \frac{1}{2}+x_{n} ; \mu\right)} \leq \frac{\sum_{i=1}^{n} \mu_{i} x_{i}}{\sum_{i=1}^{n} \mu_{i}\left(\frac{1}{2}+x_{i}\right)},
$$

where

$I\left(x_{1}, \ldots, x_{n} ; \mu\right)=m_{\ln , e_{1}}(x ; \mu), m_{f, g}(x ; \mu)=f^{-1}\left[\int_{E_{n-1}} f \circ g^{-1}(u \cdot G) d \mu(u)\right]$, $G=\left(g\left(x_{1}\right), \ldots, g\left(x_{n}\right)\right)$, and $e_{r}(t):= \begin{cases}t^{r} & r \neq 0 \\ \ln t & r=0 .\end{cases}$

\section{3. $n$-EXPONENTIAL CONVEXITY}

Motivated by the inequalities in (??) and (??), we define functionals $\Phi_{1}(f), \Phi_{2}(f), \Phi_{3}(f), \Phi_{4}(f), \Phi_{5}(f)$ and $\Phi_{6}(f)$ by

$$
\begin{aligned}
\Phi_{1}(f) & =\int_{E_{n-1}}[f(u \cdot(2 a-x))-f(u \cdot x)] d \mu(u) \\
& -f\left(\sum_{i=1}^{n} \mu_{i}\left(2 a-x_{i}\right)\right)+f\left(\sum_{i=1}^{n} \mu_{i} x_{i}\right), \\
\Phi_{2}(f) & =\sum_{i=1}^{n} \mu_{i}\left[f\left(2 a-x_{i}\right)-f\left(x_{i}\right)\right] \\
& -\int_{E_{n-1}}[f(u \cdot(2 a-x))-f(u \cdot x)] d \mu(u), \\
\Phi_{3}(f) & =\sum_{i=1}^{n} \mu_{i}\left[f\left(2 a-x_{i}\right)-f\left(x_{i}\right)\right] \\
& -f\left(\sum_{i=1}^{n} \mu_{i}\left(2 a-x_{i}\right)\right)+f\left(\sum_{i=1}^{n} \mu_{i} x_{i}\right), \\
\Phi_{4}(f) & =\int_{E_{n-1}}[f(u \cdot(a+x))-f(u \cdot x)] d \mu(u) \\
& -f\left(\sum_{i=1}^{n} \mu_{i}\left(a+x_{i}\right)\right)+f\left(\sum_{i=1}^{n} \mu_{i} x_{i}\right), \\
\Phi_{5}(f) & =\sum_{i=1}^{n} \mu_{i}\left[f\left(a+x_{i}\right)-f\left(x_{i}\right)\right]
\end{aligned}
$$


$n$-EXPONENTIAL CONVEXITY FOR LEVINSON TYPE INEQUALITIES

$$
-\int_{E_{n-1}}[f(u \cdot(a+x))-f(u \cdot x)] d \mu(u)
$$

and

$$
\begin{aligned}
\Phi_{6}(f) & =\sum_{i=1}^{n} \mu_{i}\left[f\left(a+x_{i}\right)-f\left(x_{i}\right)\right] \\
& -f\left(\sum_{i=1}^{n} \mu_{i}\left(a+x_{i}\right)\right)+f\left(\sum_{i=1}^{n} \mu_{i} x_{i}\right) .
\end{aligned}
$$

Theorem 5. Let $f:[0,2 a] \rightarrow \mathbb{R}(i=1,2,3,4,5,6)$ be such that $f \in$ $C^{3}([0,2 a]), n>1$. Then there exists $\xi \in[0,2 a]$ such that

$$
\Phi_{i}(f)=f^{\prime \prime \prime}(\xi) \cdot \Phi_{i}(\varphi)
$$

where $\varphi(x)=\frac{x^{3}}{3 !}$.

Proof. Let us denote $m=\min f^{\prime \prime \prime}$ and $M=\max f^{\prime \prime \prime}$. We first consider the following function $\phi_{1}(x)=\frac{M x^{3}}{3 !}-f(x)$. Then $\phi_{1}^{\prime \prime \prime}(x)=M-f^{\prime \prime \prime}(x) \geq 0, x \in$ $[0,2 a], i=1,2,3,4,5,6$, so $\phi_{1}$ is a 3 -convex function. Similarly, a function $\phi_{2}(x)=f(x)-\frac{m x^{3}}{3 !}$ is a 3 -convex function. Now, we use inequalities from Theorem ?? and Theorem ?? for 3-convex functions $\phi_{1}$ and $\phi_{2}$. So, we can conclude that there exists $\xi \in[0,2 a], i=1,2,3,4,5,6$, that we are looking for in (??).

Corollary 1. Let $f, h:[0,2 a] \rightarrow \mathbb{R}, i=1,2,3,4,5,6$, such that $f, h \in$ $C^{3}([0,2 a])$. Then there exists $\xi \in[0,2 a]$ such that

$$
\frac{\Phi_{i}(f)}{\Phi_{i}(h)}=\frac{f^{\prime \prime \prime}(\xi)}{h^{\prime \prime \prime}(\xi)}, i=1,2,3,4,5,6
$$

provided that the denominator of the left-hand side is non-zero.

Proof. We use the following standard technique: Let us define the linear functional

$L(\chi)=\Phi_{i}(\chi), \quad i=1,2,3,4,5,6$. Next, we define $\chi(t)=f(t) L(h)-$ $h(t) L(f)$. According to Theorem ??, applied on $\chi$, there exists $\xi \in[0,2 a]$ so that

$$
L(\chi)=\chi^{\prime \prime \prime}(\xi) \Phi_{i}(\varphi), \varphi(x)=\frac{x^{3}}{3 !}, i=1,2,3,4,5,6 .
$$

¿From $L(\chi)=0$, it follows $f^{\prime \prime \prime}(\xi) L(h)-h^{\prime \prime \prime}(\xi) L(f)=0$ and (??) is proved.

Now, let us recall some definitions and facts about exponentially convex functions (see [?]): 
Definition 1. A function $\psi: I \rightarrow \mathbb{R}$ is n-exponentially convex in the Jensen sense on $I$ if

$$
\sum_{i, j=1}^{n} \xi_{i} \xi_{j} \psi\left(\frac{x_{i}+x_{j}}{2}\right) \geq 0,
$$

hold for all choices $\xi_{1}, \ldots, \xi_{n} \in \mathbb{R}$ and all choices $x_{1}, \ldots, x_{n} \in I$.

A function $\psi: I \rightarrow \mathbb{R}$ is $n$-exponentially convex if it is $n$-exponentially convex in the Jensen sense and continuous on $I$.

Remark 1. It is clear from the definition that 1-exponentially convex functions in the Jensen sense are in fact nonnegative functions. Also, $n$-exponentially convex function in the Jensen sense are $k$-exponentially convex in the Jensen sense for every $k \in \mathbb{N}, k \leq n$.

By definition of positive semi-definite matrices and some basic linear algebra we have the following proposition:

Proposition 1. If $\psi$ is an n-exponentially convex in the Jensen sense, then the matrix $\left[\psi\left(\frac{x_{i}+x_{j}}{2}\right)\right]_{i, j=1}^{k}$ is positive semi-definite matrix for all $k \in$ $\mathbb{N}, k \leq n$. Particularly, $\operatorname{det}\left[\psi\left(\frac{x_{i}+x_{j}}{2}\right)\right]_{i, j=1}^{k} \geq 0$ for all $k \in \mathbb{N}, k \leq n$.

Definition 2. A function $\psi: I \rightarrow \mathbb{R}$ is exponentially convex in the Jensen sense on $I$ if it is $n$-exponentially convex in the Jensen sense for all $n \in \mathbb{N}$.

A function $\psi: I \rightarrow \mathbb{R}$ is exponentially convex if it is exponentially convex in the Jensen sense and continuous.

Remark 2. It is known (and easy to show) that $\psi: I \rightarrow \mathbb{R}$ is a log-convex in the Jensen sense if and only if

$$
\alpha^{2} \psi(x)+2 \alpha \beta \psi\left(\frac{x+y}{2}\right)+\beta^{2} \psi(y) \geq 0,
$$

holds for every $\alpha, \beta \in \mathbb{R}$ and $x, y \in I$. It follows that a function is logconvex in the Jensen sense if and only if it is 2-exponentially convex in the Jensen sense.

The function is log-convex if and only if it is 2-exponentially convex.

Proposition 2. If $f$ is a convex function on $I$ and if $x_{1} \leq y_{1}, x_{2} \leq$ $y_{2}, x_{1} \neq x_{2}, y_{1} \neq y_{2}$, then the following inequality is valid

$$
\frac{f\left(x_{2}\right)-f\left(x_{1}\right)}{x_{2}-x_{1}} \leq \frac{f\left(y_{2}\right)-f\left(y_{1}\right)}{y_{2}-y_{1}} .
$$

If the function $f$ is concave, the inequality is reversed. 
Lemma 2. A function $\Psi$ is log-convex on an interval $I$ if and only if, for all $a, b, c \in I, a<b<c$, it holds

$$
[\Psi(b)]^{c-a} \leq[\Psi(a)]^{c-b}[\Psi(c)]^{b-a} .
$$

We use an idea from [?] to give an elegant method of producing an $n$ exponentially convex functions and exponentially convex functions applying the above functionals on a given family with the same property (see [?]):

Theorem 6. Let $\Upsilon=\left\{f_{s}: s \in J\right\}$, where $J$ an interval in $\mathbb{R}$, be a family of functions defined on an interval $[0,2 a], i=1,2,3,4,5,6$, in $\mathbb{R}$, such that the function $s \rightarrow f_{s}\left[z_{0}, z_{1}, z_{2}, z_{3}\right]$ is n-exponentially convex in the Jensen sense on $J$ for every four mutually different points $z_{0}, z_{1}, z_{2}, z_{3} \in[0,2 a], i=$ $1,2,3,4,5,6$. Let $\Phi_{i}(f), i=1,2,3,4,5,6$, be linear functional defined as in (??)-(??). Then $s \mapsto \Phi_{i}\left(f_{s}\right)$ is an n-exponentially convex function in the Jensen sense on $J$. If the function $s \mapsto \Phi_{i}\left(f_{s}\right)$ is continuous on $J$, then it is n-exponentially convex on $J$.

Proof. For $\xi_{i} \in \mathbb{R}, i=1, \ldots, n$ and $s_{i} \in J, i=1, \ldots, n$, we define the function

$$
g(z)=\sum_{i, j=1}^{n} \xi_{i} \xi_{j} f_{\frac{s_{i}+s_{j}}{2}}(z) .
$$

Using the assumption that the function $s \rightarrow f_{s}\left[z_{0}, z_{1}, z_{2}, z_{3}\right]$ is $n$-exponentially convex in the Jensen sense, we have

$$
g\left[z_{0}, z_{1}, z_{2}, z_{3}\right]=\sum_{i, j=1}^{n} \xi_{i} \xi_{j} f_{\frac{s_{i}+s_{j}}{2}}\left[z_{0}, z_{1}, z_{2}, z_{3}\right] \geq 0,
$$

which in turn implies that $g$ is a 3 -convex function on $J$, so it is $\Phi_{k}(g) \geq$ $0, k=1,2,3,4,5,6$, hence

$$
\sum_{i, j=1}^{n} \xi_{i} \xi_{j} \Phi_{k}\left(f_{\frac{s_{i}+s_{j}}{2}}\right) \geq 0 .
$$

We conclude that the function $s \rightarrow \Phi_{k}\left(f_{s}\right)$ is $n$-exponentially convex on $J$ in the Jensen sense.

If the function $s \rightarrow \Phi_{k}\left(f_{s}\right)$ is also continuous on $J$, then $s \rightarrow \Phi_{k}\left(f_{s}\right)$ is $n$-exponentially convex by definition.

The following corollaries are an immediate consequences of the above theorem: 
Corollary 2. Let $\Upsilon=\left\{f_{s}: s \in J\right\}$, where $J$ an interval in $\mathbb{R}$, be a family of functions defined on an interval $[0,2 a]$ in $\mathbb{R}$, such that the function $s \rightarrow f_{s}\left[z_{0}, z_{1}, z_{2}, z_{3}\right]$ is exponentially convex in the Jensen sense on $J$ for every four mutually different points $z_{0}, z_{1}, z_{2}, z_{3} \in[0,2 a]$. Let $\Phi_{i}(f), i=$ $1,2,3,4,5,6$, be linear functional defined as in (??)-(??). Then $s \rightarrow \Phi_{i}\left(f_{s}\right)$ is an exponentially convex function in the Jensen sense on $J$. If the function $s \rightarrow \Phi_{i}\left(f_{s}\right)$ is continuous on $J$, then it is exponentially convex on $J$.

Corollary 3. Let $\Upsilon=\left\{f_{s}: s \in J\right\}$, where $J$ an interval in $\mathbb{R}$, be a family of functions defined on an interval $[0,2 a]$ in $\mathbb{R}$, such that the function $s \rightarrow f_{s}\left[z_{0}, z_{1}, z_{2}, z_{3}\right]$ is 2-exponentially convex in the Jensen sense on $J$ for every four mutually different points $z_{0}, z_{1}, z_{2}, z_{3} \in[0,2 a]$. Let $\Phi_{i}(f), i=1,2,3,4,5,6$, be linear functional defined as in (??)-(??). Then the following statements hold:

(i) If the function $s \rightarrow \Phi_{i}\left(f_{s}\right)$ is continuous on $J$, then it is 2-exponentially convex function on $J$. If $s \rightarrow \Phi_{i}\left(f_{s}\right)$ is additionally strictly positive, then it is also log-convex on $J$. Furthermore, the following inequality holds true:

$$
\left[\Phi_{i}\left(f_{s}\right)\right]^{t-r} \leq\left[\Phi_{i}\left(f_{r}\right)\right]^{t-s}\left[\Phi_{i}\left(f_{t}\right)\right]^{s-r}
$$

for every choice $r, s, t \in J$, such that $r<s<t$.

(ii) If the function $s \rightarrow \Phi_{i}\left(f_{s}\right)$ is strictly positive and differentiable on $J$, then for every $s, q, u, v \in J$, such that $s \leq u$ and $q \leq v$, we have

$$
\mu_{s, q}\left(\Phi_{i}, \Upsilon\right) \leq \mu_{u, v}\left(\Phi_{i}, \Upsilon\right)
$$

where

$$
\mu_{s, q}\left(\Phi_{i}, \Upsilon\right)= \begin{cases}\left(\frac{\Phi_{i}\left(f_{s}\right)}{\Phi_{i}\left(f_{q}\right)}\right)^{\frac{1}{s-q}}, & s \neq q, \\ \exp \left(\frac{\frac{d}{d s} \Phi_{i}\left(f_{s}\right)}{\Phi_{i}\left(f_{q}\right)}\right), & s=q,\end{cases}
$$

for $f_{s}, f_{q} \in \Upsilon$.

Proof. $\quad$ (i) This is an immediate consequence of Theorem ?? and Remark ??. Inequality (??) follows from Lemma ??.

(ii) Since by (i) the function $s \rightarrow \Phi_{i}\left(f_{s}\right), i=1,2,3,4,5,6$, is log-convex on $J$, that is, the function $s \rightarrow \log \Phi_{i}\left(f_{s}\right)$ is convex on $J$. So, we get

$$
\frac{\log \Phi_{i}\left(f_{s}\right)-\log \Phi_{i}\left(f_{q}\right)}{s-q} \leq \frac{\log \Phi_{i}\left(f_{u}\right)-\log \Phi_{i}\left(f_{v}\right)}{u-v}
$$


for $s \leq u, q \leq v, s \neq q, u \neq v$, and there form conclude that

$$
\mu_{s, q}\left(\Phi_{i}, \Upsilon\right) \leq \mu_{u, v}\left(\Phi_{i}, \Upsilon\right)
$$

Cases $s=q$ and $u=v$ follows from (??) as limit cases.

Remark 3. Note that the results from above theorem and corollaries still hold when two of the points $z_{0}, z_{1}, z_{2}, z_{3} \in[0,2 a]$ coincide, say $z_{1}=z_{0}$, for a family of differentiable functions $f_{s}$ such that the function $s \rightarrow f_{s}\left[z_{0}, z_{1}, z_{2}, z_{3}\right]$ is n-exponentially convex in the Jensen sense (exponentially convex in the Jensen sense, log-convex in the Jensen sense), and furthermore, they still hold when all four points coincide for a family of three differentiable functions with the same property. The proofs are obtained by (??) and suitable characterization of convexity.

\section{Applications to Stolarsky type means}

In this section, we present several families of functions which fulfil the conditions of Theorem ??, Corollary ??, Corollary ?? and Remark ??. This enable us to construct a large families of functions which are exponentially convex. For a discussion related to this problem see [?].

Example 2. Consider a family of functions

$$
\Omega_{1}=\left\{l_{s}: \mathbb{R} \rightarrow \mathbb{R}: s \in \mathbb{R}\right\}
$$

defined by

$$
l_{s}(x)= \begin{cases}\frac{e^{s x}}{s^{3}}, & s \neq 0, \\ \frac{x^{3}}{3 !}, & s=0 .\end{cases}
$$

We have $\frac{d^{3} l_{s}}{d x^{3}}(x)=e^{s x}>0$ which shows that $l_{s}$ is 3 -convex on $\mathbb{R}$ for every $s \in \mathbb{R}$ and $s \rightarrow \frac{d^{3} l_{s}}{d x^{3}}(x)$ is exponentially convex by definition. Using analogous arguing as in the proof of Theorem ?? we also have that $s \rightarrow l_{s}\left[z_{0}, z_{1}, z_{2}, z_{3}\right]$ is exponentially convex (and so exponentially convex in the Jensen sense). Using Corollary ?? we conclude that $s \rightarrow \Phi_{i}\left(l_{s}\right), i=$ $1,2,3,4,5,6$, are exponentially convex in the Jensen sense. It is easy to verify that this mapping is continuous (although mapping $s \rightarrow l_{s}$ is not continuous for $s=0)$, so it is exponentially convex. 
For this family of functions, $\mu_{s, q}\left(\Phi_{i}, \Omega_{1}\right), i=1,2,3,4,5,6$, from (??), becomes

$$
\mu_{s, q}\left(\Phi_{i}, \Omega_{1}\right)= \begin{cases}\left(\frac{\Phi_{i}\left(l_{s}\right)}{\Phi_{i}\left(l_{q}\right)}\right)^{\frac{1}{s-q}}, & s \neq q, \\ \exp \left(\frac{\Phi_{i}\left(i d \cdot l_{s}\right)}{\Phi_{i}\left(l_{s}\right)}-\frac{3}{s}\right), & s=q \neq 0 \\ \exp \left(\frac{\Phi_{i}\left(i d \cdot l_{0}\right)}{4 \Phi_{i}\left(l_{0}\right)}\right), & s=q=0 .\end{cases}
$$

Now, using (??) it is monotonous function in parameters $s$ and $q$.

We observe here that $\left(\frac{\frac{d^{n} l_{s}}{d x^{n}}}{\frac{d^{n} l_{q}}{d x^{n}}}\right)^{\frac{1}{s-q}}(\ln x)=x$ so using Corollary ?? it follows that:

$$
M_{s, q}\left(\Phi_{i}, \Omega_{1}\right)=\ln \mu_{s, q}\left(\Phi_{i}, \Omega_{1}\right), i=1,2,3,4,5,6
$$

satisfy

$$
0 \leq M_{s, q}\left(\Phi_{i}, \Omega_{1}\right) \leq 2 a, i=1,2,3,4,5,6 .
$$

So, $M_{s, q}\left(\Phi_{i}, \Omega_{1}\right)$ is monotonic mean.

Example 3. Consider a family of functions

$$
\Omega_{2}=\left\{f_{s}:(0, \infty) \rightarrow \mathbb{R}: s \in \mathbb{R}\right\}
$$

defined by

$$
f_{s}(x)= \begin{cases}\frac{x^{s}}{s(s-1)(s-2)}, & s \notin\{0,1,2\}, \\ \frac{x^{j} \ln x}{(-1)^{2-j} j !(2-j) !}, & s=j \in\{0,1,2\} .\end{cases}
$$

Here, $\frac{d^{3} f_{s}}{d x^{3}}(x)=x^{s-3}=e^{(s-3) \ln x}>0$ which shows that $f_{s}$ is 3 -convex for $x>0$ and $s \rightarrow \frac{d^{3} f_{s}}{d x^{3}}(x)$ is exponentially convex by definition. Arguing as in Example ?? we get that the mappings $s \rightarrow \Phi_{i}\left(f_{s}\right), i=1,2,3,4,5,6$ are exponentially convex. Functions (??) is now equal to:

$$
\mu_{s, q}\left(\Phi_{i}, \Omega_{2}\right)= \begin{cases}\left(\frac{\Phi_{i}\left(f_{s}\right)}{\Phi_{i}\left(f_{q}\right)}\right)^{\frac{1}{s-q}}, & s \neq q, \\ \exp \left(\frac{2 \Phi_{i}\left(f_{0} f_{s}\right)}{\Phi_{i}\left(f_{s}\right)}+\sum_{k=0}^{2} \frac{1}{k-s}\right), & s=q \notin\{0,1,2\}, \\ \exp \left(\frac{\Phi_{i}\left(f_{0} f_{s}\right)}{\Phi_{i}\left(f_{s}\right)}+\sum_{\substack{k=0 \\ k \neq s}}^{2} \frac{1}{k-s}\right), & s=q \in\{0,1,2\} .\end{cases}
$$

We observe that $\left(\frac{\frac{d^{3} f_{s}}{d x^{3}}}{\frac{d^{3} f_{q}}{d x^{3}}}\right)^{\frac{1}{s-q}}(x)=x$, so if $\Phi_{i}(i=1,2,3,4,5,6)$ are positive, then Corollary ?? yield that there exist some $\xi \in[0,2 a], i=$ 
$1,2,3,4,5,6$ such that

$$
\xi^{s-q}=\frac{\Phi_{i}\left(f_{s}\right)}{\Phi_{i}\left(f_{q}\right)}, i=1,2,3,4,5,6 .
$$

Since the function $\xi \rightarrow \xi^{s-q}$ is invertible for $s \neq q$, we then have

$$
0 \leq\left(\frac{\Phi_{i}\left(f_{s}\right)}{\Phi_{i}\left(f_{q}\right)}\right)^{\frac{1}{s-q}} \leq 2 a, i=1,2,3,4,5,6,
$$

which shows that $\mu_{s, q}\left(\Phi_{i}, \Omega_{2}\right), i=1,2,3,4,5,6$, is mean.

Example 4. Consider a family of functions

$$
\Omega_{3}=\left\{h_{s}:(0, \infty) \rightarrow \mathbb{R}: s \in(0, \infty)\right\}
$$

defined by

$$
h_{s}(x)= \begin{cases}\frac{s^{-x}}{(-\ln s)^{3}}, & s \neq 1 \\ \frac{x^{3}}{3 !}, & s=1 .\end{cases}
$$

Since $\frac{d^{3} h_{s}}{d x^{3}}(x)=s^{-x}$ is the Laplace transform of a non-negative function (see [?]) it is exponentially convex. Obviously $h_{s}$ are 3 -convex functions for every $s>0$. For this family of functions, $\mu_{s, q}\left(\Phi_{i}, \Omega_{3}\right), i=1,2,3,4,5,6$, from (??) becomes

$$
\mu_{s, q}\left(\Phi_{i}, \Omega_{3}\right)= \begin{cases}\left(\frac{\Phi_{i}\left(h_{s}\right)}{\Phi_{i}\left(h_{q}\right)}\right)^{\frac{1}{s-q}}, & s \neq q, \\ \exp \left(-\frac{\Phi_{i}\left(i d \cdot h_{s}\right)}{s \Phi_{i}\left(h_{s}\right)}-\frac{3}{s \ln s}\right), & s=q \neq 1, \\ \exp \left(-\frac{\Phi_{i}\left(i d \cdot h_{1}\right)}{4 \Phi_{i}\left(h_{1}\right)}\right), & s=q=1 .\end{cases}
$$

This is monotone function in parameters s and $q$ by (??). Using Corollary ?? it follows that

$$
M_{s, q}\left(\Phi_{i}, \Omega_{3}\right)=-L(s, q) \ln \mu_{s, q}\left(\Phi_{i}, \Omega_{3}\right), i=1,2,3,4,5,6
$$

satisfy

$$
0 \leq M_{s, q}\left(\Phi_{i}, \Omega_{3}\right) \leq 2 a .
$$

So $M_{s, q}\left(\Phi_{i}, \Omega_{3}\right)$ is monotonic mean. $L(s, q)$ is logarithmic mean defined by

$$
L(s, q)= \begin{cases}\frac{s-q}{\log s-\log q}, & s \neq q \\ s, & s=q .\end{cases}
$$


Example 5. Consider a family of functions

$$
\Omega_{4}=\left\{k_{s}:(0, \infty) \rightarrow \mathbb{R}: s \in(0, \infty)\right\}
$$

defined by

$$
k_{s}(x)=\frac{e^{-x \sqrt{s}}}{(-\sqrt{s})^{3}} .
$$

Since $\frac{d^{3} k_{s}}{d x^{3}}(x)=e^{-x \sqrt{s}}$ is the Laplace transform of a non-negative function (see [?]) it is exponentially convex. Obviously $k_{s}$ are 3 -convex functions for every $s>0$. For this family of functions, $\mu_{s, q}\left(\Phi_{i}, \Omega_{4}\right), i=1,2,3,4,5,6$, from (??) becomes

$$
\mu_{s, q}\left(\Phi_{i}, \Omega_{4}\right)= \begin{cases}\left(\frac{\Phi_{i}\left(k_{s}\right)}{\Phi_{i}\left(k_{q}\right)}\right)^{\frac{1}{s-q}}, & s \neq q, \\ \exp \left(-\frac{\Phi_{i}\left(i d \cdot k_{s}\right)}{2 \sqrt{s} \Phi_{i}\left(k_{s}\right)}-\frac{3}{2 s}\right), & s=q .\end{cases}
$$

This is monotone function in parameters $s$ and $q$ by (??). Using Corollary ?? it follows that

$$
M_{s, q}\left(\Phi_{i}, \Omega_{4}\right)=-(\sqrt{s}+\sqrt{q}) \ln \mu_{s, q}\left(\Phi_{i}, \Omega_{4}\right), i=1,2,3,4,5,6
$$

satisfy

$$
0 \leq M_{s, q}\left(\Phi_{i}, \Omega_{4}\right) \leq 2 a .
$$

So $M_{s, q}\left(\Phi_{i}, \Omega_{4}\right)$ is monotonic mean.

Acknowledgements. The research of the author was supported by the Croatian Ministry of Science, Education and Sports, under the Research Grant $117-1170889-0888$.

\section{REFERENCES}

[1] M. Anwar, J. Pečarić, Cauchy's means of Levinson type, JIPAM 9(4) (2008), Article 120.

[2] M. Anwar, J. Pečarić, On logarihmic convexity for Ky-Fan inequality, J. Ineqqual. Appl. 2008, Article ID 870950.

[3] M. Anwar, J. Jakšetić, J. Pečarić, Atiq Ur Rehman, Exponential convexity, positive semi-definite matrices and fundamental inequalities, J. Math.Ineqial. 4(2) (2010), 171189.

[4] K. E. Atkinson, An Introduction to Numerical Analysis, 2nd ed., Wiley, New York, 1989.

[5] W. Ehm, M. G. Genton, T. Gneiting, Stationary covariance associated with exponentially convex functions, Bernoulli 9(4) (2003), 607-615.

[6] J. Jakšetić, J. Pečarić, Exponential Convexity Method, J. Convex Anal. 20(1) (2013), 181-197. 
[7] N. Levinson, Generalization of an inequality of Ky Fan, J. Math. Anal. Appl. 80 (1964), 133-134.

[8] E. Neuman, Inequalities involving multivariate convex functions II, Proc. Math. Soc. 109 (1990), 965-974.

[9] E. Neuman, C.E.M. Pearce, J. Pečarić, V. Šimić, The generalised Hadamard inequality, g-convexity and functional Stolarsky means, Bull. Austral. Math. Soc. 68 (2003), 303-316.

[10] Z. Pavić, J. Pečarić, A. Vukelić, Exponential convexity and Jensen inequality for divided differences, J. Math. Ineqial. 5(2) (2011), 157-168.

[11] J. E. Pečarić, An inequality for 3-convex function, J. Math. Anal. Appl. 90 (1982), 213-218.

[12] J. E. Pečarić, F. Proschan and Y. L. Tong, Convex functions, partial orderings, and statistical applications, Mathematics in science and engineering, vol. 187 Academic Press, 1992.

[13] J. Pečarić, J. Perić, Improvements of the Giaccardi and the Petrović inequality and related results, An. Univ. Craiova Ser. Mat. Inform., 39(1) (2012), 65-75.

[14] G. Roqia, J. Pečrić, A. Vukelić, n-exponential convexity of divided differences and related Stolarsky type means, Math. Ineq. Appl. 16(4)(2013), 1043-1063.

[15] D. V. Widder, The Laplace transform, Princeton Univ. Press, New Jersey, 1941. 


\section{n-ЕКСПОНЕНЦИЈАЛНА КОНВЕКСНОСТ ЗА НЕРАВЕНСТВА ОД ВИДОТ НА ЛЕВИНСОН И ПОВРЗАНИ СО НИВ СРЕДИНИ ОД ВИДОТ НА СТОЛАРСКИ}

Ана Вукелиќ

Р е $з$ и м е

Почнувајќи од резултатот даден во [8], каде авторот го дава обопштеното неарвенство на Адамар, даваме генерализација на неравенството на Левинсон (види [9]) и поврзани со него неаравенства. Исто така ја испитуваме експоненцијалната конвексност на разликите од левата и десната страна на овие неравенства. Користејќи ги тие разлики, добиваме нови експоненцијално конвексни функции. Тие се искористени во проучувањето на средини од типот на Столарски.

Faculty of Food Technology and Biotechnology, Mathematics department, University of Zagreb, Pierottijeva 6, 10000 Zagreb, Croatia

E-mail address: avukelic@pbf.hr 